\title{
Neprilysin inhibition: A brief review of past pharmacological strategies for heart failure treatment and future directions
}

\author{
Erik H. Howell, Scott J. Cameron \\ Department of Medicine, Division of Cardiology, and Aab Institute for Cardiovascular Research, \\ University of Rochester School of Medicine and Dentistry, Rochester, NY, United States
}

\begin{abstract}
Heart failure (HF) is a manifestation of aberrant vascular responses and remains a public health concern with a worldwide prevalence of around 23 million and a 5-year mortality numerically equivalent to many cancers. Over the last two decades, mortality from HF reached a plateau with current pharmaceutical agents and mechanical cardiac support. In the last several years, various "novel" pharmaceutical agents have been tested in clinical trials and ultimately met with disappointment, showing only incremental benefit in the treatment of HF. Designing a HF drug with enhanced efficacy over existing agents seemed like a Sisyphean task. Yet again, pharmaceutical chemists have demonstrated their prowess in lateral thinking by developing a vasoactive agent which is a co-crystallized compound of valsartan and sacubitril in a one-to-one molar ratio; the former molecule belongs to a family of agents that are the current standard of care for HF and the latter molecule is a novel agent which inhibits neprilysin - a neutral endopeptidase found in human plasma which alters neurohumoral responses. In July of 2015, a drug which is a combination of valsartan and sacubitril was formally licensed by the United States Food and Drug Administration for the treatment of HF. This review describes the evolution of HF medications focusing on rational drug design with the first HF medication, the beta-adrenergic receptor antagonist. We then discuss the biochemical and physiological properties of sacubitril/valsartan which likely lead to its dramatic ability to ameliorate HF mortality. (Cardiol J 2016; 23, 6: 591-598)
\end{abstract}

Key words: neprilysin, sacubitril, valsartan endopeptidase, heart failure, cardiomyopathy, LCZ696

\section{Introduction}

Heart failure (HF) is a complex clinical syndrome driven by inadequate circulatory blood flow for the metabolic demands of vital organs such as the brain and kidneys. Effectively, the heart pumping function begins to fail, hence the term, HF. In the western world, the leading cause of HF overwhelmingly is the result of diseased coronary arteries which supply the heart muscle with blood. This is termed ischemic cardiomyopathy [1]. Other causes of acquired HF include: uncontrolled high blood pressure, viral infections, autoimmune disease, drug toxicity, metabolic derangements, as well as rare inherited genetic defects - all grouped under the umbrella of non-ischemic cardiomyopathy [2].

Heart failure may manifest physiologically as an inefficient ability of the heart muscle to contract

Address for correspondence: Scott J. Cameron, PhD, MD, 601 Elmwood Avenue, Box 679, Rochester, NY 14642, USA, tel: 585-276-7694, fax: 585-276-0073, e-mail: scott_cameron@urmc.rochester.edu

Received: 09.06.2016 Accepted: 03.08.2016 
(systolic dysfunction) or an inefficient ability of the heart muscle to relax (diastolic dysfunction, also referred to as heart failure with preserved ejection fraction [HFpEF]) [3]. HF manifests as a variety of symptoms including: fatigue, shortness of breath, chest pain, abdominal pain, abdominal distension, weight gain, and swelling of the lower extremities. When HF is appropriately treated, patients are stated to have compensated HF and, when acutely ill and very symptomatic, patients are stated to have decompensated HF [4]. Medications used to treat HF symptoms have evolved over the last few decades. Initial therapies focused on downstream targets such as renal tubules (i.e. diuretics) and myocardial contractility (i.e. inotropes) which enabled symptom relief, but offered no mortality benefit. Contemporary pharmacologic therapy has moved upstream in the cellular signal transduction pathway, targeting neurohormonal modulation involving angiotensin converting enzyme inhibitors (ACEIs), angiotensin receptor blockers (ARBs), beta-blockers and mineralocorticoid receptor antagonists (MRAs) which has resulted in summative mortality benefit [5]. In addition, percutaneous devices including implantable defibrillators, dual ventricular pacing via 'cardiac resynchronization therapy', and surgically implanted ventricular assist devices have further extended the life of $\mathrm{HF}$ patients [6-10]. Over the last 5 years, cardiac mechanical circulatory support devices have improved and grown from acute support/bridge therapies to destination therapies which overshadowed pharmacological management of HF. Mechanical devices are invasive, expensive, and create additional complications in the management of patients with an already complicated disease such as HF. Until last year, it was felt that no further refinements could be made upon existing pharmacologic agents to improve patient outcomes. In as much as the beta-blockers were discovered by the late Scottish physician, pharmacologist, and Nobel Laureate Sir James Whyte [11], subsequent years saw the development of ACEIs, ARB, MRAs, until this year when pharmaceutical chemists once again demonstrated their skill in drug formulation to create the perfect compound of two existing drugs which surpass the current standard of medical care for patients with $\mathrm{HF}$.

\section{What works: Pharmacological successes in heart failure treatment \\ Basic laboratory scientists have struggled for years to improve upon HF medications in part because it was believed that $\mathrm{HF}$ is a disease that}

can be best controlled by altering cellular signaling pathways most responsible for the pathophysiological events in HF. HF involves excessive activation of the sympathetic nervous system, the synthesis and release of hormonal agents, and activation of aberrant cellular signal transduction pathways inside myocardial cells and in surrounding cells which comprise heart tissue [12-15]. Much of the initial effort into understanding and treating HF was directed toward the beta-adrenergic receptor signaling pathway and the angiotensin receptor signaling pathways - both of which are excessively activated in HF.

Without question, the beta-adrenergic receptor antagonists were an extraordinary medical discovery and truly were the initial revolutionary treatment of HF. It is fair to say that the success of discovering and implementing beta adrenergic receptor antagonists was attributed to Sir James Whyte Black and his team of chemists who made a scientific observation in the early 1960 s that dichloroisoproterenol (DCI) appeared to function as a beta-adrenergic receptor antagonist. They then realized that chemical modifications of this molecule would be required for it to have efficacy on living tissue. The structural changes to DCI produced the candidate pharmaceutical agent pronethalol, which would become the foundation of the family of beta-adrenergic receptor antagonists that would be later refined for the treatment of HF $[16,17]$. This lesson clearly highlights the need to integrate scientific endeavors between pharmaceutical and synthetic organic chemists who design and synthesize drugs with pharmacologists who study the effect of medications on tissue, and clinicians who will eventually prescribe the medications. It is somewhat fortuitous and potentially revealing that Dr. Black - while initially trained in clinical medicine - devoted his entire career to pharmaceutical chemistry and so was able to simultaneously fulfill the role of both scientist and physician. Drug discovery and refinement in our highly regulated society generally does not function this way today.

While stimulation of the beta1-adrenergic receptor is responsible for the inotropic (contractile) function of cardiac myocytes, it initially seemed counterintuitive that beta1-receptor antagonists such as bisoprolol, metoprolol, and carvedilol could improve HF symptoms and prolong life in patients with HF $[1,16,18-20]$. Cardiac myocyte toxicity through excessive beta1-stimulation in fact involves a cascade of intracellular biochemical events including intracellular calcium overload, 
programmed cell death (apoptosis), and remodeling of the extracellular matrix [20,21]. It became clear that biochemical events responsible for inotropic incompetence - in part through excessive sympathetic nervous system activation - involve covalent modification of the beta1-adrenergic receptor through phosphorylation by intracellular protein kinases, subsequent beta1 desensitization and down-regulation by intracellular trafficking $[9,15,17,22]$. It is unclear why only a few medications among the beta-adrenergic receptor antagonists have mortality benefit in HF but, nonetheless, beta-blockers partly reverse sympathetic nervous system-induced receptor internalization by recycling some beta1 receptors to the cell surface and restoring inotropic competence. Thus, by synthesizing antagonists against cell surface receptors and inhibitors of enzymes involved in post-receptor signaling mediators including second messengers, patients with HF began to live longer. Upon initiating beta1-adrenergic receptor antagonists in the early treatment of HF, it may not have been appreciated that beta1-adrenergic receptors in the kidney promote the release of the hormone renin, which further augments the hormonal aberrancies of HF [23]. As such, beta1-adrenergic antagonists have pleotropic effects in the management of HF.

The 1980s and 1990s harbored in clinical evidence for the treatment of chronic systolic $\mathrm{HF}$ involving antagonism of the renin-angiotensin-aldosterone system (RAAS) to counteract the maladaptive neurohormonal changes. In brief, renin is a circulating proteolytic enzyme produced by the kidney which converts the plasma peptide angiotensinogen to angiotensin I. Angiotensin I is converted to angiotensin II (Ang II) by the enzyme ACE which lines the innermost layer of the blood vessel wall. Ang II when produced in excess in patients with failing hearts promotes narrowing of blood vessels, sodium retention directly, and by secretion of aldosterone from the kidney, sodium retention indirectly and plasma volume expansion (Fig. 1). Over the years, multiple attempts have been made to interfere with the various components of the RAAS by employing enzyme inhibitors against the hormone renin and ACE and competitive pharmacological antagonists against the Ang II and aldosterone receptors [1, 24]. Of these various agents, only renin inhibitors were plagued by poor bioavailability when taken orally and failed to show marked clinical efficacy for $\mathrm{HF}$ management, ultimately gaining approval by the United States Food and Drug Administration for hypertension management [21]. Nonetheless, a valiant effort persists today to assess the efficacy of the renin inhibitor alisikiren in a highly selective multinational HF study ATMOSPHERE [25]. The pivotal CONSENSUS group study and the SOLVD trial indicated enalapril offered significant mortality benefit as compared to placebo [26, 27]. The mortality benefit offered by ACEI therapy was confirmed when examining other medications in the class, such as captopril and ramipril [28, 29]. Early data suggested angiotensin receptor blockade offered similar mortality benefit as ACEI and was confirmed in the larger study, ELITE II, comparing losartan with captopril [30, 31]. Candesartan stood alone to improve mortality as compared to placebo and solidified ARBs in systolic HF as demonstrated by the CHARM study, while the VALIANT study showed clinical efficacy by blocking ARBs with valsartan [32, 33]. Aldosterone receptor antagonists spironolactone and eplerenone have clear efficacy and mortality benefit in patients with systolic $\mathrm{HF}$ in the RALES and EPHESUS studies, respectively, and remain the standard of adjunctive medical therapy for systolic HF management today.

After around a decade of 'false starts', a new class of medication for HF management emerged around 2010 in the medication ivabradine. Based on the principle that systolic HF results from excessive sympathetic activation, and this triggers pathological intracellular signal transduction pathways [15, 34-37], we recently saw the implementation of ivabradine in well-controlled clinical studies [38, 39]. Ivabradine was the first class of HF medications which directly blocks ion channels in electrical nodal tissue which generate the action potential, thus limiting cardiac pacemaker activity and also the increase in heart rate common to excessive sympathetic activation in HF. It therefore stands to reason that the most efficacious agents used to treat the signaling aberrancies in HF, such as the beta-blockers, ACEIs and ARBs, would eventually reach a glass ceiling, and attempts to develop more efficacious drugs against these targets were met by incremental clinical benefits against $\mathrm{HF}$ which was and still is a major individual and societal burden. With the exception of ivabradine's recent promising data, it was clear to physicians, basic scientists, and pharmaceutical chemists that the specter of HF casts a very long shadow and something different was needed.

\section{What did not work: Pharmacological disappointments in heart failure treatment \\ The pathophysiology of HF culminates in myocardial cell stretch through excessive volume}




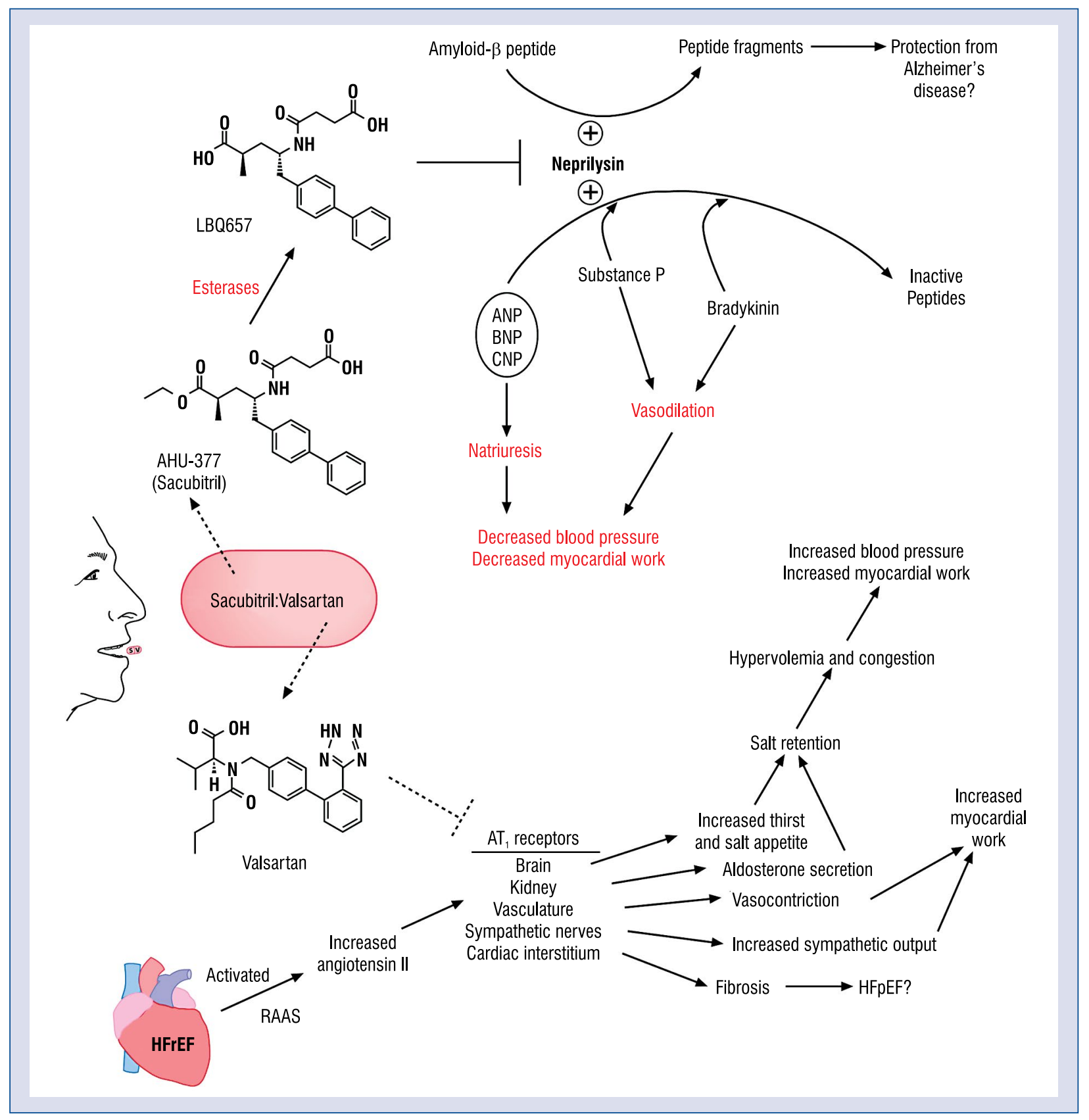

Figure 1. Physiological effects of neprilysin and angiotensin receptor antagonism in vivo; abbreviations - see text.

and pressure and this promotes the synthesis, storage, and granular release of vasoactive peptides such as atrial natriuretic peptide (ANP) and brain natriuretic peptide (BNP) from cardiac myocytes [40-42]. ANP and BNP are among the neurohumoral mediators which serve as markers of $\mathrm{HF}$ severity, but also may alleviate some of the maladaptive physiological processes in decompensated HF. ANP and BNP, as their names suggest, promote natriuresis and therefore osmosis in kidney tubules of patients in HF, with a net diuretic response.
These effects restore fluid homeostasis which becomes dysregulated in patients with HF. Indeed, when the mechanical function of the heart is compromised in HF, blood vessel capillary hydrostatic pressures increases, and fluid extravasation occurs according to the Starling equation [43]. Diuretic medications promote fluid excretion through the kidneys and treat the effects of a dysregulated, failing heart. The use of diuretic medications has always been - and therefore always will be a natural component of the drug armamentarium 
for treating decompensated HF. Diuretics, however, do not address the underlying pathophysiological causes of HF because their perpetual use serves only to augment the RAAS which is the aberrant hormonal cascade of HF [44].

Effectively, the synthesis and secretion of endogenous natriuretic peptide agents appears to be a protective mechanism to counteract adverse pathophysiological processes in HF. The natriuretic and diuretic effect of ANP and BNP also opposes the dysregulated activity of the RAAS, which are common in etiology of decompensated HF. As peptide signaling mediators, ANP and BNP also stimulate G-protein coupled receptors (GPCRs) on vascular smooth muscle cells which promote the synthesis of the second messenger cyclic guanosine monophosphate (cGMP) which decrease vascular smooth muscle tone [15, 45, 46]. When vascular smooth tone decreases, peripheral vascular resistance decreases, and the net effect is decreased capillary hydrostatic pressure, and improved cardiac output by decreasing afterload on the heart muscle.

For the physiological reasons noted above, it would seem intuitive that supplementing ANP or BNP intravenously should promote natriuresis, diuresis, and improve cardiac output in patients with HF. BNP supplementation did indeed reverse some subjective symptoms as well as some of the aberrant neurohumoral and hemodynamic derangements in patients with HF, but a well-controlled clinical trial failed to demonstrate mortality benefit in these patients compared to placebo and the drug is no longer endorsed for clinical use in patients with $\mathrm{HF}[46,47]$.

\section{What we always hoped for: A pharmaceutical} breakthrough in heart failure treatment

Neprilysin is a membrane-bound metalloendopeptidase with a coordinated zinc ion within the catalytic site. Neprilysin is fairly ubiquitous, with expression in cardiac myocytes, endothelial cells, and vascular smooth muscle cells. Neprilysin is responsible for the inactivation and degradation of the natriuretic peptides as well as other circulating vasodilating mediators including substance $\mathrm{P}$ and bradykinin (Fig. 1) [48, 49].

Accordingly, it has been shown that inhibitors of metallo-endopeptidase promote a natriuretic as well as a diuretic effect, and they decrease blood pressure by promoting relaxation of resistance arterioles [50]. In some respects, it may be perceived that neprilysin inhibition is not dissimilar to natriuretic peptide supplementation and so may be as ineffective as the clinical studies which in- vestigated the effect of natriuretic peptide infusion on HF morbidity and mortality. The OVERTURE study compared the neprilysin inhibitor omapatrilat to the ACEI enalapril in treating HF, finding only marginally improved clinically efficacy with omapatrilat [51], and thus neprilysin as a drug target for $\mathrm{HF}$ retreated into obscurity for over a decade.

The much vaunted PARADIGM-HF trial delivered everything that physicians and scientists long hoped for: a well-controlled, high quality clinical investigation showing a novel pharmaceutical agent which significantly improved upon the current standard of care for HF $[52,53]$. The ingenuity behind sacubitril/valsartan lies in the decision to administer a compound of a neprilysin inhibitor as a pro-drug (sacubatril) with an angiotensin receptor antagonist (valsartan). This combination was proposed to maximize the protective effects of endogenous natriuretic and vasodilating mediators whilst minimizing the deleterious effects of angiotensin II accumulation. PARADIGM-HF tested sacubitril/valsartan, which is a robust inhibitor of RAAS, demonstrating an overwhelming mortality benefit comparing sacubitril/valsartan to the ACEI enalapril that the study was stopped early at the recommendation of the clinical trial data and safety monitoring board.

In addition, sacubitril/valsartan also reduced hospitalization for HF in one fifth of the patient population studied compared to enalapril [52]. An important consideration is that endogenous neprilysin not only degrades natriuretic and vasodilating molecules, but also Ang II which drives dysregulated hemodynamics and myocardial remodeling in HF $[54,55]$. After much thought, clinical pharmacologists proposed that the once daily dosing of the neprilysin inhibitor which was attempted in past clinical trials may be a reason behind its marginal benefit over ACEI in prior clinical studies [47, 56], and they began working with pharmaceutical chemists to solve two problems: 1 . Improve the bioavailability of a drug which functions as a neprilysin inhibitor; 2 . Block the hemodynamic and neurohumoral effects of increased circulating Ang II concentration which is common to both the pathophysiology of $\mathrm{HF}$ and the use of a neprilysin inhibitor. Sacubitril/valsartan is a 1:1 molar ratio of the ARB valsartan and the neprilysin inhibitor sacubitril. Sacubatril is an inactive pro-drug (AHU377) which is converted to an active neprilysin inhibitor (LBQ657) through esterase-mediated de-ethylation following oral administration [57, 58]. The physiological effects of combined neprilysin with angiotensin receptor antagonism which 
generally promote vasodilation, natriuresis, and decrease blood pressure, cardiac workload, and adverse remodeling of the cardiac interstitium are shown in schematic form (Fig. 1). When considering any new therapeutic agent, a fatal mistake and one that may challenge the longevity of any new therapeutic agent is when clinicians work in parallel to rather than in unison with pharmaceutical chemists when the stage of drug formulation is reached. Appropriate care should be directed toward the chemistry of drug synthesis and potential drug modification by metabolic enzymes in the body. In the case of sacubitril/valsartan, subsequent pharmacokinetic studies confirmed that synthesizing valsartan as an anionic salt of molecular weight 957.99 and empirical formula: $\mathrm{C}_{48} \mathrm{H}_{55} \mathrm{~N}_{6} \mathrm{O}_{8} \mathrm{Na}_{3} 2.5 \mathrm{H}_{2} \mathrm{O}$ in sacubitril/valsartan was an excellent decision which increased valsartan bioavailability on average by $50 \%$ compared to ingestion of equimolar and equivalent doses of valsartan and sacubitril as separate drugs [56, 58]. When administered as the co-crystalized compound sacubitril/valsartan, the individual agents valsartan and LBQ657 dissociate, and have a blood elimination half-life of around $11 \mathrm{~h}$, reaching a plasma steady state concentration in 3 days. This makes sacubitril/valsartan suitable for twice daily dosing [59-61]. Pharmaceutical chemist and clinical pharmacologists have highly developed skills in drug synthesis and optimizing the pharmacodynamic effect of a drug, while physicians are uniquely qualified to evaluate the gaps in drug efficacy. Similar to the success of the beta-adrenergic antagonists, the success of sacubitril/valsartan, therefore, is a clear reminder to both the scientific and the medical community that pharmaceutical chemists and physicians working together accomplish greater things for patient care than working separately.

\section{Neprilysin inhibition with an angiotensin receptor antagonist: Cautionary remarks}

Based on the profound effect sacubitril/valsartan has on cardiac afterload (Fig. 1), a real concern is the propensity for this combined therapy to precipitate symptomatic hypotension, as was described in the PARADIGM-HF Trial [52] and echoed with similar prevalence in a past clinical study of a neprilysin inhibitor with an ACEI [62]. This is especially important given that patients with chronic systolic HF generally also have dysregulated sympathetic tone as well as impairment in renal blood flow, and raises the issues of unpredictability in determining appropriate patient dosing schedules.

Neprilysin in an important enzyme in the homeostasis of and, in particular, the degradation of amyloid-beta-peptide in the brain and the eye - a peptide for which excessive accumulation and aberrant deposition is well known in the etiology of Alzheimer's disease as well as certain forms of macular degeneration [63, 64]. Accumulation of amyloid peptide closely mimics the phenotype of Alzheimer's disease in a murine model [65] and, in fact, an active area of investigation in the treatment of Alzheimer's disease is to employ therapeutic agents to augment neprilysin activity [59]. This raises the very real concern that in our quest to find the next 'silver bullet' for the treatment of HF, we may inadvertently be predisposing patients to neurological and ophthalmic dysfunction from the off-target effects that are inevitable for any therapeutic agent, and occasionally underappreciated until the stage of post-marketing surveillance of the drug by the Food and Drug Administration Adverse Event Reporting System. Further research into the effect of neprilysin inhibition in the development of neurodegenerative disease is therefore warranted.

\section{Future directions in the pharmacological management of heart failure}

A patient population that deserves special attention is those patients with HFpEF. Diastolic heart dysfunction or 'heart stiffening' is an expected expression of the aging heart and, as we become more skilled at treating disease and more sophisticated in diagnostic imaging, there is a somewhat misleading trend of an increased prevalence of HFpEF [66]. While HFpEF as a clinical disorder can be a secondary manifestation of myocardial hypertrophic and infiltrative diseases [60, 61], the biochemical and cellular mechanisms leading to the disorder are poorly defined, though interstitial cell fibrosis is believed to be a common endpoint [67]. It has been proposed that $\mathrm{HFpEF}$ may be a consequence of microvascular dysfunction and subsequent myocardial fibrosis which evades conventional myocardial imaging of epicardial coronary vessels [68]. Others have shown that proliferation of cardiac fibroblast in the extracellular matrix and deposition of collagen is commonplace in the heart of patients with $\mathrm{HFpEF}$ $[69,70]$. Various sophisticated laboratory investigations have shown the presence of the Ang II receptor on fibroblasts and, when stimulated, collagen deposition into the extracellular matrix 
occurs [71-73]. The involvement of the RAAS is important for remodeling of the extracellular matrix, and this in turn affects the ability of the heart muscle to relax and is therefore a prerequisite for $\mathrm{HFpEF}$ [74]. With this fact in mind, the failure of an aldosterone receptor antagonist in the TOPCAT study to meet its primary endpoint for clinical efficacy in patients with HFpEF was surprising [75]. Nonetheless, hospitalization for HF was less in the drug treatment arm. Moreover, by subgroup analysis, the primary outcome for drug treatment was actually met in patients from the Americas but not Eastern Europe. While a regional difference in drug effect was hypothesized, another interpretation is that pharmacological blockade of the RAAS appears to be a necessary but insufficient step in the treatment of HFpEF. Neprilysin inhibitors were also shown to prevent myocardial hypertrophy but not fibrosis in animal models of $\mathrm{HF}$ [61, 76, 77]. We know that neprilysin inhibition can attenuate myocardial remodeling in humans. The prospect that sacubitril/valsartan may also have efficacy in $\mathrm{HFpEF}$ is therefore also being tested, with smaller scale clinical trials already showing efficacy [28].

\section{Conclusions}

Sacubitril/valsartan may indeed self-declare as a silver bullet in the treatment of systolic as well as diastolic HF. Clinicians do not always possess the research armamentarium required to evaluate and synthesize new medications, but they are in the unique position to evaluate gaps in current medical therapy and to ask important questions. Pharmacologists and pharmaceutical chemists do not always appreciate the nuances of clinical care, but they are highly skilled in synthesizing and evaluating the effect of drugs in living organisms. Since sacubitril/valsartan is essentially a cleverly formulated version of two medications that have been available for over a decade, the remarkable success of sacubitril/valsartan in ameliorating HF serves as a signpost to remind the medical community and the pharmaceutical industry that working together maximizes the academic impact of any endeavor and, in fact, it is our moral obligation for effective patient care.

\section{Acknowledgements \\ SJC is supported by the following grants: $\mathrm{NIH}$ 5T32HL066988-1 and K08HL128856.}

\section{Conflict of interest: None declared}

\section{References}

1. Guidelines for the diagnosis of heart failure. The Task Force on Heart Failure of the European Society of Cardiology. Eur Heart J, 1995; 16: 741-751.

2. Teerlink JR, Goldhaber SZ, Pfeffer MA. An overview of contemporary etiologies of congestive heart failure. Am Heart J, 1991; 121: 1852-1853.

3. Flachskampf FA, Biering-Sorensen T, Solomon SD et al. cardiac imaging to evaluate left ventricular diastolic function. JACC Cardiovasc Imaging, 2015; 8: 1071-1093.

4. Cotter G, Felker GM, Adams KF et al. The pathophysiology of acute heart failure: Is it all about fluid accumulation? Am Heart J, 2008; 155: 9-18.

5. Sacks CA, Jarcho JA, Curfman GD. Paradigm shifts in heart-failure therapy: A timeline. N Engl J Med, 2014; 371: 989-991.

6. Kutyifa V, Goldenberg I, Moss AJ. Lessons learned from the Multicenter Automatic Defibrillator Implantation Trial-Cardiac Resynchronization Therapy (MADIT-CRT). Trends Cardiovasc Med, 2016; 26: 137-146.

7. Abshire M, Dennison Himmelfarb CR, Russell SD. Functional status in left ventricular assist device-supported patients: A literature review. J Card Fail, 2014; 20: 973-983.

8. Stevenson LW, Miller LW, Desvigne-Nickens P et al. Left ventricular assist device as destination for patients undergoing intravenous inotropic therapy: A subset analysis from REMATCH (Randomized Evaluation of Mechanical Assistance in Treatment of Chronic Heart Failure). Circulation, 2004; 110: 975-981.

9. Bardy GH, Lee KL, Mark DB et al. Amiodarone or an implantable cardioverter-defibrillator for congestive heart failure. N Engl J Med, 2005; 352: 225-237.

10. Moss AJ, Brown MW, Cannom DS et al. Multicenter automatic defibrillator implantation trial-cardiac resynchronization therapy (MADIT-CRT): Design and clinical protocol. Ann Noninvasive Electrocardiol, 2005; 10: 34-43.

11. Black JW, Crowther AF, Shanks RG et al. A New adrenergic betareceptor antagonist. Lancet, 1964; 1: 1080-1081.

12. Dhakal P, Liu K, Kozman $\mathrm{H}$ et al. Renal denervation in heart failure: A new therapeutic paradigm. Clin Med Insights Cardiol, 2015; 9: 101-104.

13. Nijst P, Verbrugge FH, Grieten L et al. The pathophysiological role of interstitial sodium in heart failure. J Am Coll Cardiol, 2015; 65: 378-388.

14. Floras JS, Ponikowski P. The sympathetic/parasympathetic imbalance in heart failure with reduced ejection fraction. Eur Heart J, 2015; 36: 1974-1982.

15. Triposkiadis F, Karayannis G, Giamouzis G et al. The sympathetic nervous system in heart failure physiology, pathophysiology, and clinical implications. J Am Coll Cardiol, 2009; 54: 1747-1762.

16. Effect of metoprolol $\mathrm{CR} / \mathrm{XL}$ in chronic heart failure: Metoprolol $\mathrm{CR} / \mathrm{XL}$ Randomised Intervention Trial in Congestive Heart Failure (MERIT-HF). Lancet, 1999; 353: 2001-2007.

17. Lymperopoulos A, Rengo G, Koch WJ. GRK2 inhibition in heart failure: Something old, something new. Curr Pharm Des, 2012; 18: 186-191.

18. Jain PC, Khandelwal Y, Tripathi ON. Adrenoceptor blocking agents. 2. 2-(alpha-Hydroxyarylmethyl)-3,3-dimethylaziridines, a new class of selective beta2-adrenoceptor antagonists. J Medicinal Chemistry, 1978; 21: 68-72.

19. Packer M, Coats AJ, Fowler MB et al. Effect of carvedilol on survival in severe chronic heart failure. N Engl J Med, 2001; 344: 1651-1658.

20. The Cardiac Insufficiency Bisoprolol Study II (CIBIS-II): A randomised trial. Lancet, 1999; 353: 9-13.

21. Jensen C, Herold P, Brunner HR. Aliskiren: The first renin inhibitor for clinical treatment. Nat Rev Drug Discov, 2008; 7: 399-410.

22. Brodde OE, Bruck H, Leineweber K. Cardiac adrenoceptors: Physiological and pathophysiological relevance. J Pharmacol Sci, 2006; 100: 323-337.

23. van Zwieten PA, de Jonge A. Interaction between the adrenergic and renin-angiotensin-aldosterone-systems. Postgraduate Med J, 1986; 62 (Suppl. 1): 23-27.

24. Solomon SD, Zile M, Pieske B et al. The angiotensin receptor neprilysin inhibitor LCZ696 in heart failure with preserved ejection fraction: A phase 2 double-blind randomised controlled trial. Lancet, 2012; 380: 1387-1395.

25. Krum H, McMurray JJ, Abraham WT et al. The Aliskiren Trial to Minimize OutcomeS in Patients with HEart failure trial (ATMOSPHERE): Revised statistical analysis plan and baseline characteristics. Eur J Heart Fail, 2015; 17: 1075-1083.

26. Effects of enalapril on mortality in severe congestive heart failure. Results of the Cooperative North Scandinavian Enalapril Survival Study (CONSENSUS). The CONSENSUS Trial Study Group. N Engl J Med, 1987; 316: 1429-1435.

27. Effect of enalapril on survival in patients with reduced left ventricular ejection fractions and congestive heart failure. The SOLVD Investigators. N Engl J Med, 1991; 325: 293-302. 
28. Effect of ramipril on mortality and morbidity of survivors of acute myocardial infarction with clinical evidence of heart failure. The Acute Infarction Ramipril Efficacy (AIRE) Study Investigators. Lancet, 1993; 342: 821-828.

29. Pfeffer MA, Braunwald E, Moye LA et al. Effect of captopril on mortality and morbidity in patients with left ventricular dysfunction after myocardial infarction. Results of the survival and ventricular enlargement trial. The SAVE Investigators. N Engl J Med, 1992; 327: 669-677.

30. Pitt B, Poole-Wilson PA, Segal R et al. Effect of losartan compared with captopril on mortality in patients with symptomatic heart failure: Randomised trial: The Losartan Heart Failure Survival Study ELITE II. Lancet, 2000; 355: 1582-1587.

31. Pitt B, Segal R, Martinez FA et al. Randomised trial of losartan versus captopril in patients over 65 with heart failure (Evaluation of Losartan in the Elderly Study, ELITE). Lancet, 1997; 349: 747-752.

32. Pfeffer MA, Swedberg K, Granger CB et al. Effects of candesartan on mortality and morbidity in patients with chronic heart failure: The CHARM-Overall programme. Lancet, 2003; 362: 759-766.

33. Voors AA, van Veldhuisen DJ. Role of angiotensin receptor blockers in patients with left ventricular dysfunction: Lessons from CHARM and VALIANT. Int J Cardiol, 2004; 97: 345-348.

34. Struthers A, Krum H, Williams GH. A comparison of the aldosterone-blocking agents eplerenone and spironolactone. Clin Cardiol, 2008; 31: 153-158.

35. Pitt B, Williams G, Remme W et al. The EPHESUS trial: Eplerenone in patients with heart failure due to systolic dysfunction complicating acute myocardial infarction. Eplerenone Post-AMI Heart Failure Efficacy and Survival Study. Cardiovasc Drugs Ther, 2001; 15: 79-87.

36. Pitt B, Zannad F, Remme WJ et al. The effect of spironolactone on morbidity and mortality in patients with severe heart failure. Randomized Aldactone Evaluation Study Investigators. N Engl J Med, 1999; 341: 709-717.

37. Pitt B, Remme W, Zannad F et al. Eplerenone, a selective aldosterone blocker, in patients with left ventricular dysfunction after myocardial infarction. N Engl J Med, 2003; 348: 1309-1321.

38. Bohm M, Swedberg K, Komajda M et al. Heart rate as a risk factor in chronic heart failure (SHIFT): The association between heart rate and outcomes in a randomised placebo-controlled trial. Lancet, 2010; 376: 886-894.

39. Fox K, Ford I, Ferrari R. Ivabradine in stable coronary artery disease. N Engl J Med, 2014; 371: 2435.

40. Kimura K, Yamaguchi Y, Horii M et al. ANP is cleared much faster than BNP in patients with congestive heart failure. Eur J Clin Pharmacol, 2007; 63: 699-702.

41. Kasama S, Toyama T, Kumakura $\mathrm{H}$ et al. Effects of intravenous atrial natriuretic peptide on cardiac sympathetic nerve activity in patients with decompensated congestive heart failure. J Nucl Med, 2004; 45: 1108-1113.

42. Mills RM, LeJemtel TH, Horton DP et al. Sustained hemodynamic effects of an infusion of nesiritide (human b-type natriuretic peptide) in heart failure: A randomized, double-blind, placebo-controlled clinical trial. Natrecor Study Group. J Am Coll Cardiol, 1999; 34: 155-162.

43. Woodcock TE, Woodcock TM. Revised Starling equation and the glycocalyx model of transvascular fluid exchange: An improved paradigm for prescribing intravenous fluid therapy. Br J Anaesth, 2012; 108: 384-394.

44. Houston BA, Kalathiya RJ, Kim DA, Zakaria S. Volume overload in heart failure: An evidence-based review of strategies for treatment and prevention. Mayo Clin Proc, 2015; 90: 1247-1261.

45. Hobbs RE, Mills RM. Endogenous B-type natriuretic peptide: a limb of the regulatory response to acutely decompensated heart failure. Clin Cardiol, 2008; 31: 407-412.

46. O'Connor CM, Starling RC, Hernandez AF et al. Effect of nesiritide in patients with acute decompensated heart failure. N Engl J Med, 2011; 365: 32-43.

47. Massien C, Azizi M, Guyene TT et al. Pharmacodynamic effects of dual neutral endopeptidase-angiotensin-converting enzyme inhibition versus angiotensin-converting enzyme inhibition in humans. Clin Pharmacol Ther, 1999; 65: 448-459.

48. Worthley MI, Corti R, Worthley SG. Vasopeptidase inhibitors: Will they have a role in clinical practice? Br J Clin Pharmacol, 2004; 57: 27-36.

49. Swedberg K. Heart failure therapies in 2014: Mixed results for heart failure therapies. Nat Rev Cardiol, 2015; 12: 73-75.

50. Northridge DB, Jardine AG, Alabaster CT et al. Effects of UK 69578 : A novel atriopeptidase inhibitor. Lancet, 1989; 2: 591-593.

51. Buggey J, Mentz RJ, DeVore AD, Velazquez EJ. Angiotensin receptor neprilysin inhibition in heart failure: Mechanistic action and clinical impact. J Card Fail, 2015; 21: 741-750.

52. McMurray JJ, Packer M, Desai AS et al. Angiotensin-neprilysin inhibition versus enalapril in heart failure. N Engl J Med, 2014; 371: 993-1004.
53. Packer M, McMurray JJ, Desai AS et al. Angiotensin receptor neprilysin inhibition compared with enalapril on the risk of clinical progression in surviving patients with heart failure. Circulation, 2015; 131: 54-61.

54. Macdonald PS. Combined angiotensin receptor/neprilysin inhibitors: A review of the new paradigm in the management of chronic heart failure. Clin Ther, 2015; 37: 2199-2205.

55. Birkenfeld AL, Adams F, Schroeder C et al. Metabolic actions could confound advantageous effects of combined angiotensin II receptor and neprilysin inhibition. Hypertension, 2011; 57: e4-e5.

56. Gu J, Noe A, Chandra P et al. Pharmacokinetics and pharmacodynamics of LCZ696, a novel dual-acting angiotensin receptor-neprilysin inhibitor (ARNi). J Clin Pharmacol, 2010; 50: 401-414.

57. Ksander GM, Ghai RD, de Jesus R et al. Dicarboxylic acid dipeptide neutral endopeptidase inhibitors. J Med Chemistry, 1995; 38: 1689-1700.

58. Vardeny O, Miller R, Solomon SD. Combined neprilysin and renin-angiotensin system inhibition for the treatment of heart failure. JACC Heart Fail, 2014; 2: 663-670.

59. Chen PT, Chen ZT, Hou WC et al. Polyhydroxycurcuminoids but not curcumin upregulate neprilysin and can be applied to the prevention of Alzheimer's disease. Scientific Reports, 2016; 6: 29760.

60. Desai A, Fang JC. Heart failure with preserved ejection fraction: hypertension, diabetes, obesity/sleep apnea, and hypertrophic and infiltrative cardiomyopathy. Heart Fail Clin, 2008; 4: 87-97.

61. van Heerebeek L, Borbely A, Niessen HW et al. Myocardial structure and function differ in systolic and diastolic heart failure. Circulation, 2006; 113: 1966-1973.

62. Packer M, Califf RM, Konstam MA et al. Comparison of omapatrilat and enalapril in patients with chronic heart failure: The Omapatrilat Versus Enalapril Randomized Trial of Utility in Reducing Events (OVERTURE). Circulation, 2002; 106: 920-926.

63. Vodovar N, Paquet C, Mebazaa A et al. Neprilysin, cardiovascular, and Alzheimer's diseases: the therapeutic split? Eur Heart J, 2015; 36: 902-905.

64. Feldman AM, Haller JA, DeKosky ST. Valsartan/sacubitril for heart failure: Reconciling disparities between preclinical and clinical investigations. JAMA, 2016; 315: 25-26.

65. Baranello RJ, Bharani KL, Padmaraju V et al. Amyloid-beta protein clearance and degradation $(\mathrm{ABCD})$ pathways and their role in Alzheimer's disease. Curr Alzheimer Res, 2015; 12: 32-46.

66. Owan TE, Redfield MM. Epidemiology of diastolic heart failure. Prog Cardiovasc Dis, 2005; 47: 320-332.

67. Lekavich CL, Barksdale DJ, Neelon V, Wu JR. Heart failure preserved ejection fraction $(\mathrm{HFpEF})$ : An integrated and strategic review. Heart Fail Rev, 2015; 20: 643-653.

68. Mohammed SF, Hussain S, Mirzoyev SA et al. Coronary microvascular rarefaction and myocardial fibrosis in heart failure with preserved ejection fraction. Circulation, 2015; 131: 550-559.

69. Fan D, Takawale A, Basu R et al. Differential role of TIMP2 and TIMP3 in cardiac hypertrophy, fibrosis, and diastolic dysfunction. Cardiovasc Res, 2014; 103: 268-280.

70. Westermann D, Lindner D, Kasner M et al. Cardiac inflammation contributes to changes in the extracellular matrix in patients with heart failure and normal ejection fraction. Circ Heart Fail, 2011; 4: 44-52.

71. Siddesha JM, Valente AJ, Sakamuri SS et al. Angiotensin II stimulates cardiac fibroblast migration via the differential regu-lation of matrixins and RECK. J Mol Cell Cardiol, 2013; 65: 9-18.

72. Barison A, Grigoratos C, Todiere G, Aquaro GD. Myocardial interstitial remodelling in non-ischaemic dilated cardiomyopathy: Insights from cardiovascular magnetic resonance. Heart Fail Rev, 2015; 20: 731-749.

73. Chen K, Mehta JL, Li D et al. Transforming growth factor beta receptor endoglin is expressed in cardiac fibroblasts and modulates profibrogenic actions of angiotensin II. Circ Res, 2004; 95: 1167-1173.

74. Weber KT, Brilla CG. Pathological hypertrophy and cardiac interstitium. Fibrosis and renin-angiotensin-aldosterone system. Circulation, 1991; 83: 1849-1865.

75. Pitt B, Pfeffer MA, Assmann SF et al. Spironolactone for heart failure with preserved ejection fraction. N Engl J Med, 2014; 370: 1383-1392.

76. Mishima T, Tanimura M, Suzuki G et al. Effects of chronic neutral endopeptidase inhibition on the progression of left ventricular dysfunction and remodeling in dogs with moderate heart failure. Cardiovasc Drugs Ther, 2002; 16: 209-214.

77. $\mathrm{Pu} \mathrm{Q}$, Larouche I, Schiffrin EL. Effect of dual angiotensin converting enzyme/neutral endopeptidase inhibition, angiotensin converting enzyme inhibition, or AT1 antagonism on coronary microvasculature in spontaneously hypertensive rats. Am J Hypertens 2003; 16:931-937. 